\title{
A device for automated laser delivery in retinal photocoagulation
}

\author{
A. M. HAMILTON AND R. M. L. DORAN
}

From the Retinal Diagnostic Department, Moorfields Eye Hospital, City Road, London EC1V 2PD

SUMMARY We report a modification to the argon-krypton laser (Lasertek Model AK 41) which allows optional automatic operation. This is a safe, time-saving device for use in cases requiring extensive retinal laser treatment.

In cases of vascular retinopathy involving ischaemia and neovascularisation indirect treatment with laser photocoagulation may require several hundred to a few thousand applications to be made in a single session. For each application the pedal switch is Correspondence to Mr R. M. L. Doran. pressed and released and the operator may judge the duration of each shot by the speed of pedal release or set the duration on the control box. Repeated rapid use of the pedal is tiring and may cause unequal burns due to variable laser exposure.

By selecting the automatic mode the laser may be

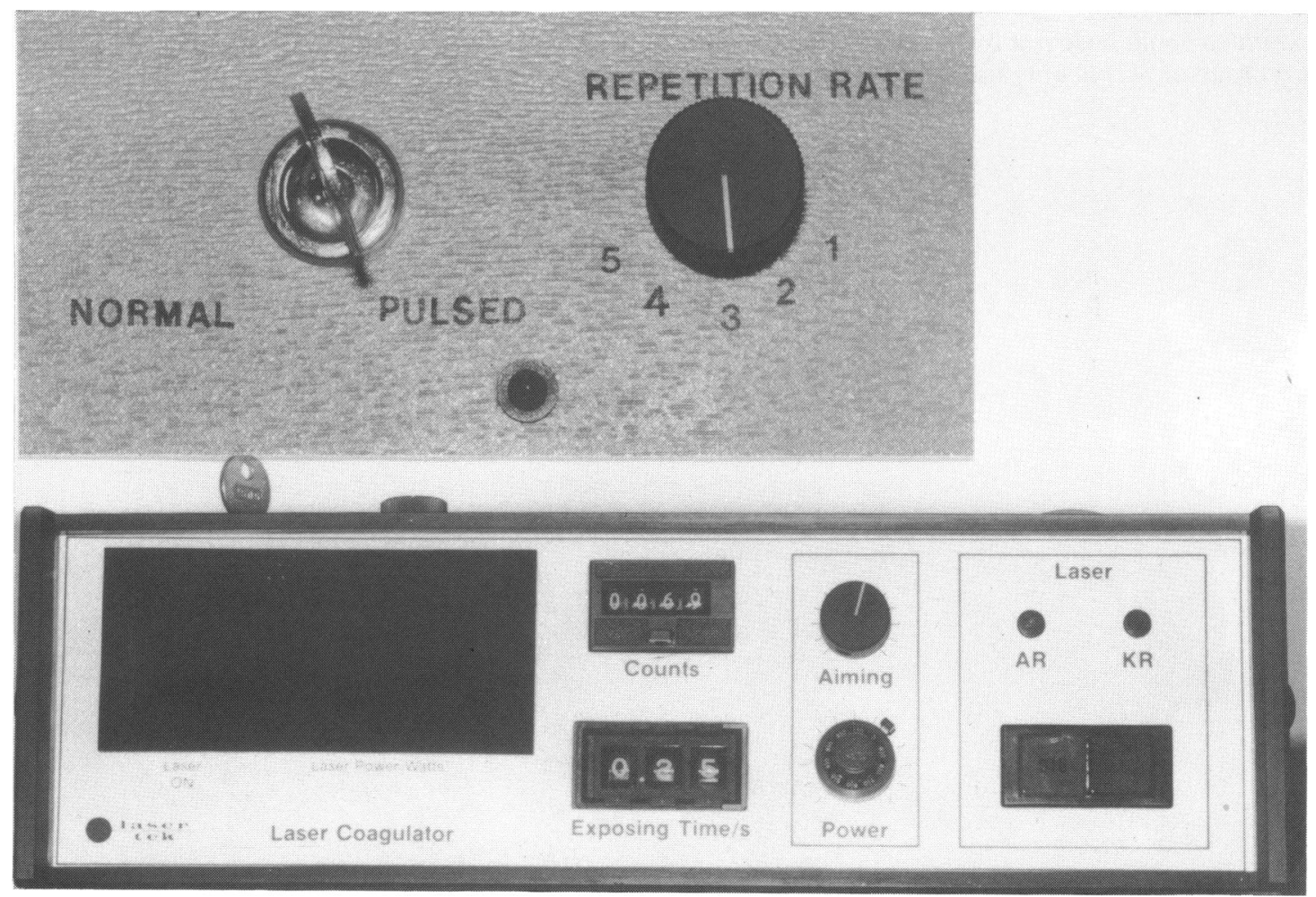

Fig. 1 Below: The control box showing exposure duration setting and application counter. Above: Key switch for automatic use (PULSED refers to the automatic mode, not to the laser beam characteristics). 
Table 1 Repetition rate

\begin{tabular}{lllll}
\hline Setting & \multicolumn{5}{l}{ Duration of exposure (seconds) } \\
\cline { 2 - 5 } & 0.02 & 0.05 & 0.1 & 0.2 \\
\hline 1 & 73 & 60 & 44 & 30 \\
2 & 45 & 39 & 32 & 25 \\
3 & 29 & 27 & 22 & 20 \\
4 & 19 & 19 & 16 & 14 \\
5 & 7 & 7 & 6 & 6 \\
\hline
\end{tabular}

Figures give approximate numbers of applications in 10 seconds.

fired at a set rate intermittently for as long as the pedal is depressed. The protective filters, which have been modified to allow optimal view, remain in position during such automatic use. The automatic facility is obtained by turning the key switch on top of the control box anticlockwise and selecting one of 5 repetition rates on the adjacent dial (Fig. 1). The actual rate of firing is determined by the repetition rate in conjunction with the exposure duration setting and may be varied from about one to 6 shots per second (Table 1). Single shots may still be applied, each preceded by an interval.

It is important to set the power setting and exposure duration as precisely as possible to obtain the desired burn strength. Test applications are required to assess the strength of the burn. Variations of energy absorption require occasional changes in the power setting during treatment, and it is intended to incorporate a new potentiometer dial on the slit-lamp for this purpose.

Automatic use is not suitable in the macular region nor in uncooperative patients. It is of particular value in panretinal coagulation, when its use can significantly shorten the procedure, making it less arduous for both patient and surgeon.

We thank Mr K. S: Sehmi for his photographic work and Mrs C. Penn for her secretarial help. 